\title{
The Reconstruction of Drawn Architecture
}

\author{
FABRIZIO I. APOLLONIO, FEDERICO FALLAVOLLITA, ELISABETTA C. GIOVANNINI, \\ RICCARDO FOSCHI and SALVATORE CORSO \\ University of Bologna, Italy
}

\begin{abstract}
Among the many situations that arise in the process of digital hypothetical 3D reconstruction, a particular case is that of unbuilt projects. Such projects were designed but remained on paper, with the result that, although documented by technical drawings, they posed the typical problems that are common to other cases, which range from 3D reconstructions of transformed architecture to destroyed/lost buildings and parts of towns.

These case studies, which start from old drawings, have to be implemented by different kinds of documentary sources that are able to provide-by means of evidence, induction, deduction, and analogyinformation characterized by different levels of uncertainty and related to different levels of accuracy.

All methods adopted in a digital hypothetical 3D reconstruction process show us that the goal of the researchers is to be able to make explicit, or at least intelligible, a synthetic/communicative level representative of the value of the reconstructive process that is behind a particular result. This can be accomplished through a graphical system.

The result of a reconstructive process defines three aspects of a structure, intimately related to each other: shape (geometry, size, spatial position); appearance (surface features); and constitutive elements (physical form, stratification of building/manufacturing systems).

This paper presents the use of 3D models as a means to document and communicate the shape and appearance of unbuilt architecture while tracing the uncertainty and accuracy that characterizes each of the reconstructed elements.
\end{abstract}

Key words:

3D digital modeling, 3D Virtual reconstruction, Architectural drawing, Reconstruction process.

SDH Reference:

Fabrizio I. Apollonio et al. 2017. The reconstruction of drawn architecture, SDH, 1, 2, 380-395.

DOI : $10.14434 / \mathrm{sdh} . \mathrm{v} 1 \mathrm{i} 2.23243$

\section{INTRODUCTION}

The topic of the reconstruction of the artifacts of a vanished, lost or non-existent past can be traced to the age of Humanism in fifteenth century Italy. During that period, when interest in classical culture and history was keen, some scholars began to collect and study Greek and Roman antiquities,

Author's address: Fabrizio I. Apollonio, Federico Fallavollita, Elisabetta C. Giovannini Riccardo Foschi and Salvatore Corso, Dipartimento di Architettura, Università di Bologna, Viale del Risorgimento 2, 40136 Bologna, Italy; email: fabrizio.apollonio@unibo.it; federico.fallavollita@unibo.it; elisabettacaterina.giovannini@unibo.it; riccardo.foschi2@unibo.it; salvatore.corso2@unibo.it

Permission to make digital or hardcopies of part or all of this work is granted without fee according to the open access policy of SDH.

(c) 2017 SDH Open Access Journal

Studies in Digital Heritage, Vol. 1, No. 2, Publication date: December 2017 
initiating, in the field of art and architecture, the study of Vitruvius' De architectura, the edito princeps of which dates to 1486 [cf. Vitruvio 1556]. These interests led both to the birth of archaeology and also to the publication of important new treatises on architecture, including, notably, Leon Battista Alberti's De re aedificatoria (1450), Sebastiano Serlio's I sette libri dell'architettura (1537), and Andrea Palladio's I quattro libri dell'architettura (1570). These treatises contributed to the development of the architectural culture of the Renaissance. Since the time of the humanists, the topic of reconstruction (in the beginning as a physical model and nowadays as a digital one) has continued to interest scholars in a wide range of disciplines that study the past, including history, archaeology, paleontology, architecture, art, literature, etc.

Ciriaco d'Ancona (1391-1452) was an early humanist with a strong interest in the dcoumentation and reconstruction of the monuments of the past. He was a merchant and diplomat from Ancona, a selftaught humanist and antiquarian. Ciriaco d'Ancona was "the most enterprising and prolific recorder of Greek and Roman antiquities, particularly inscriptions, in the fifteenth century, and the general accuracy of his records entitles him to be called the founding father of modern classical archaeology" [Bodnar, Foss, 2003].

Bodnar 1960 presented a biography of Ciriaco as well as a detailed analysis of the inscriptions that he collected throughout his journeys along Mediterranean littoral and in the Middle East. Also included was a map of sites mentioned, and ten plates with reproductions of Ciriaco's original drawings. According to Bodnar and Mitchell [Bodnar, 1960; Mitchell, 1974], Ciriaco was the first modern European to describe the Acropolis of Athens and the Parthenon. Thanks to him, his contemporaries could have the first hypothetical drawing of the Parthenon, which Ciriaco called by its name, instead of "the church of Santa Maria," as it had been known until then. After his visit in 1436 Thus, Ciriaco wrote that he had admired "mirabile Palladis Divae marmoreum templum, divum quippe opus Phidiae" ["the admirable marble temple of the goddess Athena, a truly divine work of Phidias"; Nizzo, 2010].

One of the plates published by Bodnar allows us to compare Ciriaco's Parthenon drawings with that of Giuliano da Sangallo (1445-1516), which represents an interpretation of two of Ciriaco's original drawings: one dedicated to the front and the second one, now lost, of the frieze. Sangallo's drawing is very different: it changes the proportions of the elevation of Ciriaco's Parthenon; removes three columns from the front colonnade; adds Composite capitals to the Doric columns; rearranges the metopes from the south side to the north (the side represented in his drawing); and puts, just behind and above the pediment of the temple, a kind of attic supported by columns placed on pedestals.

Ciriaco's methodological approach was based on (a) first-hand investigation of the monument, a direct approach to the ancient spolia, tested in the field; (b) study of the texts of ancient authors, whom he called nobiles auctores (quoting among others Pliny's Naturalis Historia XXXVI, 18, and also the Aristotelian De Mundo, 6399 b 34); and (c) comparison with the stylistic characteristics of contemporary works presenting the same stylistic features. In contrast, Giuliano da Sangallo's approach was based on his interpretation of Ciriaco's two drawings and on his own architectural knowledge gained from the study of ancient monuments that he had found, surveyed and drawn. 


\section{3D RECONSTRUCTION AFTER AN ARCHITECTURAL DRAWING}

These two cases of interpretative drawing of the Parthenon well represent the typical problems of the reconstruction process since ancient times: the proper use of documentary sources, their interpretation, and the transparency of the process that led to the reconstructive (hypothetical) result. For the completion of the reconstruction process, and then in the case of the virtual reconstruction for defining the shape, size and material characteristics of each element of an artifact, we are often faced with the presence/absence, certainty/uncertainty, and accuracy/inaccuracy of information. Such information is derived from sources that we have, and where these are deficient, by the possibility of finding specific reference material useful to the formulation, more or less reliable, of the hypothetical reconstructions. Each source or reference utilized is characterized, therefore, with regard to information that can be inferred and which is related to the reconstruction process by a specific degree of uncertainty or reliability and by a degree of accuracy.

To bridge the gap between the presence/absence of information and the resultant knowledge/ignorance and then to formulate a hypothesis by expressing a form of ignorance about a proposition, we should understand the category of ignorance that is relevant. Unfortunately, from an epistemological point of view, a fixed definition of uncertainty/reliability/ambiguity does not exist. There is not a standard and shared method to visualize this kind of uncertainty [Kensek, 2007; Strothotte et al., 1999; Pang et al., 1997; Zuk et al., 2005; Perlinska, 2014; Bakker et al., 2003; Borghini, and Carlani, 2011; Apollonio et al., 2013; Vico Lopez, 2012; Georgiou, and Hermon, 2011; Demetrescu, 2015; Apollonio, 2016; Lulof et al., 2013]. There is a wide range of definitions with reference to the various fields of knowledge and different approaches, some less generic than others, concerning both the uncertainty and the ways of representing it. There is, not surprisingly, a copious literature on this topic, including surveys of the problem [Edwards and Nelson, 2001; Otto et al., 2010; Bonneau et al., 2014; Masuch and Strothotte, 1998; Thomson et al., 2005; Brodlie et al., 2012; Pang et al., 1997; Pang and Furman, 1994; Boukhelifa and Duke, 2009].

Some research fields- e.g., spatial modeling, law, medicine, geology, as well as archaeology and the history of art and architecture-have defined inferential reasoning and incomplete evidence, on the one hand, to formally express beliefs in order to make a judgement or evaluate a hypothesis, and, on the other hand, to have explored the notions of mathematically and visually expressing uncertainty. When uncertainty is related to a lack of information arising from randomness, such as results by chance, we call it aleatory: it is objective that the results differ each time an experiment is run, depending on chance, and thus we use probabilistic modeling to describe it. When uncertainty is due to a lack of knowledge, which means knowledge that in principle could be known, but in practice is not, we refer to the type of uncertainty called epistemic: it is subjective; it is uncertain due to errors that practically cannot be controlled and can be described by non-probabilistic modeling. [Bonneau et al., 2014]

The reconstruction process, using a given set of documentary sources, requires a procedural pipeline based on a semantic system, able to define a set of preparatory and operational phasescomplementary between them-in order to investigate the sources and, when missing any information, the related or integrative references [Apollonio et al., 2013; Münster et al., 2016; PfarrHarfst, 2016]. 
Such types of information may be used and elaborated in order to define a structured modeling procedure based on different levels of interpretation, characterized by a progressively increasing ordinal scale of uncertainty [Apollonio et al., 2013; Apollonio, 2016]:

1) reconstruction based on archaeological/architectural evidence

2) reconstruction based on original drawings

3) reconstruction based on design data related to stylistic/coeval similarities

4) reference to treatises, books, journals, articles or architectural guidelines written by the author (architect/artist) of the artifact studied

5) reference to treatises, books, journals, articles or the manual that the author (if known) has or could have used as his own reference

6) interpretative hypotheses related to a specific architectural style and/or historical period

7) interpretative hypotheses based on static analysis, referring to coeval construction systems, constructively plausible and compatible with the project

8) reconstructive conjectures, failing references

Each of these categories is defined, in fact, by its own degree of accuracy related to geometric, dimensional, formal, material and construction data that we can derive, infer or assume from the documentary source(s) available for each single element of that case study.

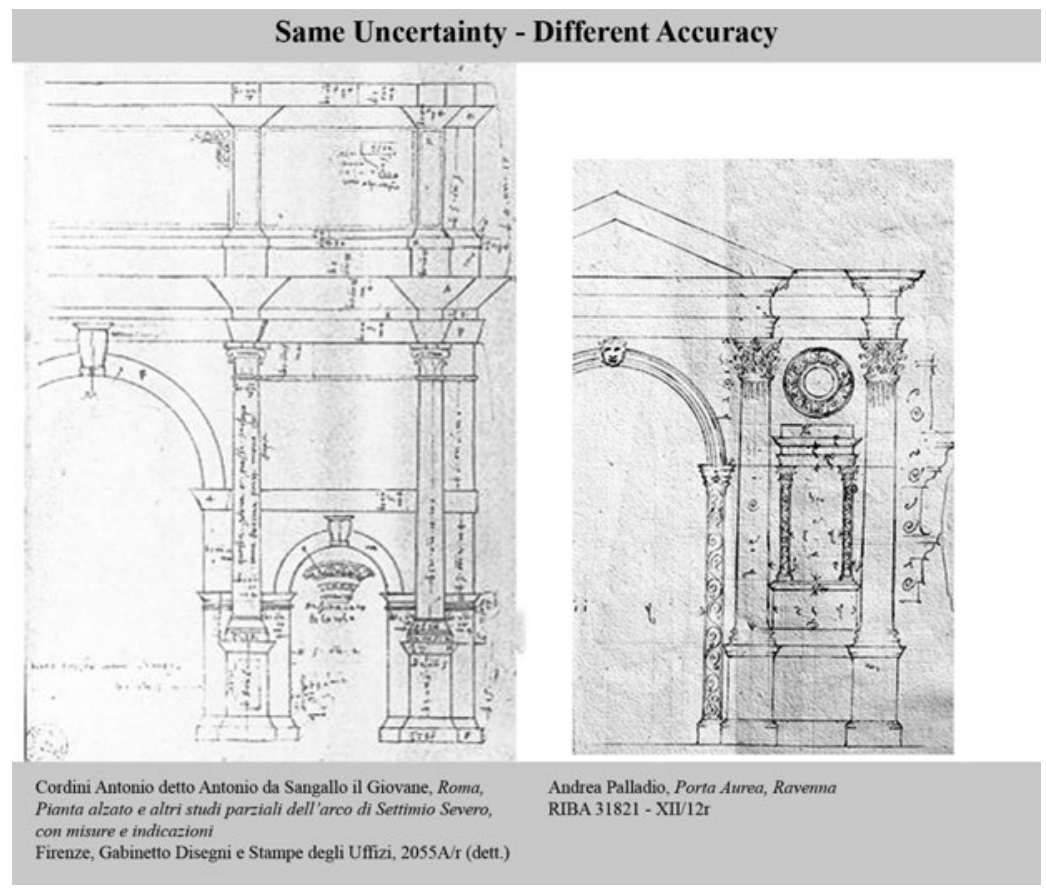

Figure 1. Comparison between two different kinds of sources (left: Arch of Septimius Severus, Roman Forum, Rome; right: Porta Aurea, Ravenna), characterized by same uncertainty and by different accuracy. 
The determination of the shape of an object (geometry, size, spatial position) is based on proceduresa sort of "playback" of the architectural design and building process-embodied through the definition of a given degree of accuracy, connected, in turn, with the scale to which the process of modeling could be related (Fig. 1).

In the pre-digital design process, the scale of representation of an object/artifact defined the accuracy of information obtainable from it. With the advent of digital tools, modeling and representation can coexist separately. Modeling procedure defines the shape of an object up to a scale of 1:1 (related to dimensional accuracy chosen based on the unit's working environment in which we operate); representation displays the model produced with its own attributes and up to the desired level of detail. The shape (dimensional and geometric consistency) of an artifact becomes the first area where we need to clarify the level of geometric accuracy of the reconstruction process, and therefore it defines its semantic structure that hinges on the same valuation method. Therefore, the resulting uncertainty validation of the reconstructed model is based on different levels of interpretation of source data, characterized by a progressively increasing level of uncertainty of the geometrical definition (accuracy) of the constitutive elements of the artifact.

Archaeological/architectural evidence (reality-based data; stratigraphic record), original drawings (survey/plans/sketches characterized by a low level of dimensional accuracy, etc.) refers to the hypothetical reconstruction based on evidence derived from the architectural or archaeological artifacts or real items. The level of accuracy of real-based data, therefore, is determined only by the intrinsic accuracy of the instrument or by the surveying and measuring technology used to detect the object (Fig. 2).

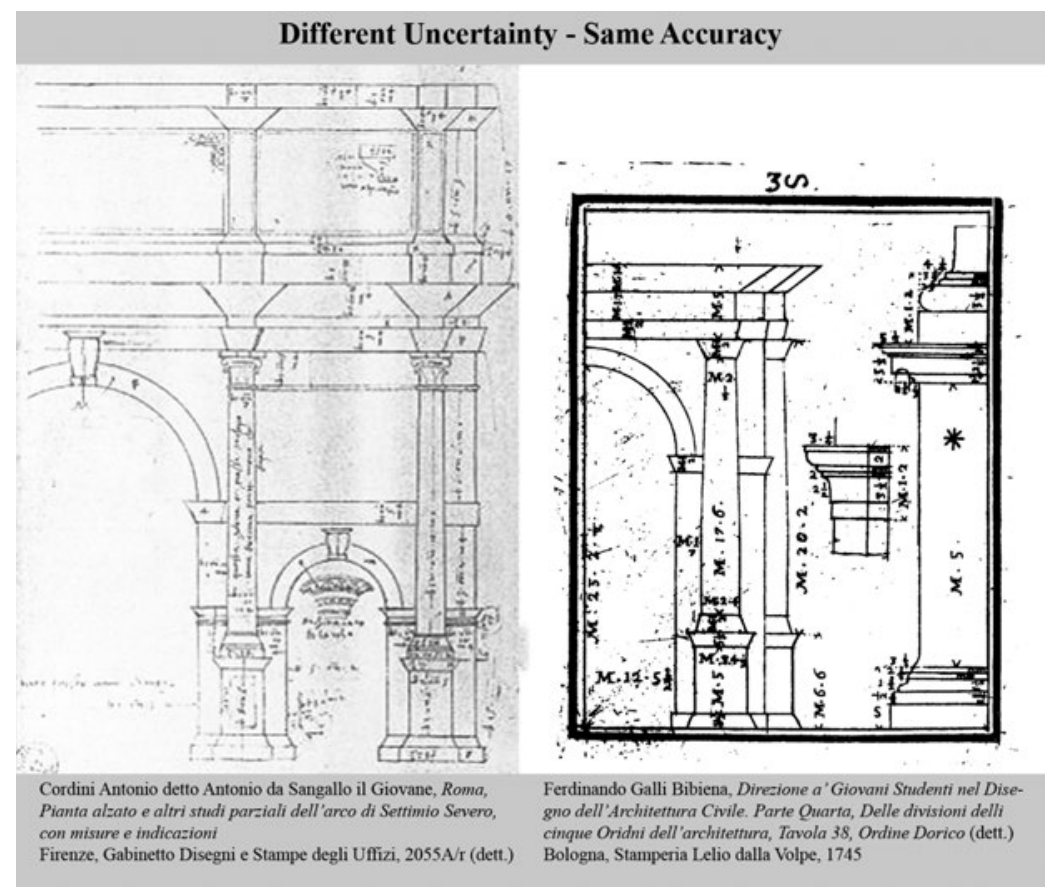

Figure 2. Comparison between two different kinds of sources on the same monument (Arch of Septimius Severus, Roman Forum, Rome), characterized by different uncertainty and the same accuracy. 
The conjectural hypothetical reconstruction, which, owing to a lack of any documentary source or references, depends on the researchers' "common/scientific sense," is based on their accumulated knowledge or, whenever necessary, on their imagination. Sometimes the design data are related to stylistic/contemporary similarities, references to treaties, books, journals, articles or architectural guidelines written by the author, interpretative hypotheses related to a specific architectural style and/or historical period or referring to contemporary construction systems.

Among the different types of sources, we could use are 3D models/findings; data from 3D survey (TLS, SfM); technical drawings (historical, cadastral, maps, 2D survey); multimedia (animation, video, rendering, photos); 2.5D representation (reliefs, bas-reliefs); drawings (engravings, sketches, paintings); and texts/verbal descriptions. However, in the case of projects of unbuilt architecture, drawings, sketches, images and pictorial representations are the only sources to which we can refer to develop a hypothetical reconstruction (Fig. 3).

\section{TWO-DIMENSIONAL DRAWINGS AND THE PRECISION OF 3D MODELS}

Therefore, with reference to the scale of uncertainties, the reconstruction of architecture designed only in accordance with drawings or sketches, is characterized as a process attributable to the second degree of certainty (see list above). The type and graphical characteristics of the sources, as we saw above, also affect the degree of accuracy and therefore the detail of the reconstructive hypothesis.

We have accumulated nearly fifteen years of experience in the field of reconstruction of architectural projects that were never built. Over the years, we have reconstructed and published many projects of various architects. Besides the virtual reconstruction of unbuilt buildings or other architectural structures, we place emphasis on research concerning three-dimensional models as a research method, transfer of knowledge, and new forms of memory.

The research for procedures, methods and techniques applied to the digital representation of architecture and their educational use leads us to utilize three-dimensional models for the knowledge, reading and analysis of representative cases of architecture. The designs of Andrea Palladio remained on paper, so did those Palladio published in I quattro libri, the designs by ClaudeNicholas Ledoux (1736-1806) for the ideal city of Chaux, the design for the Foro Bonaparte by Giovanni Antonio Antolini (1753-1841) and the utopian designs for "Cesena Nuova" and "Cesenatico Nuovo" by Mauro Guidi (1761-1829). They represent a sufficiently broad sample of typological experimentation.

The drawing and the representation, in this case, become the means for the development of interpretive models in which, despite well-structured guidelines, the intention of reproducing the original design idea is mediated by the subjective vision of the represented project. The documentation of this cognitive process is an integral part of the ongoing debate on transparency of information and the configurative possibilities of architectural elements in the 3D virtual reconstructions. Here we shall attempt to give some answers to the questions raised in this debate. 


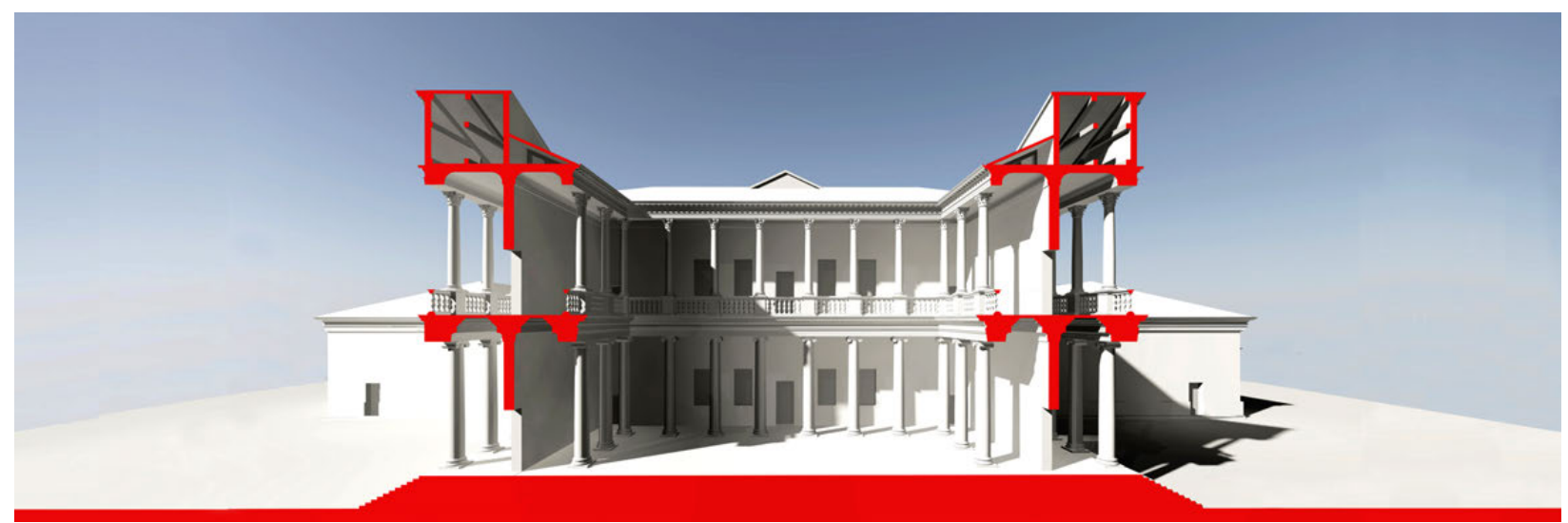

Figure 3. Virtual reconstruction: A. Palladio, Villa Mocenigo. Perspective longitudinal section

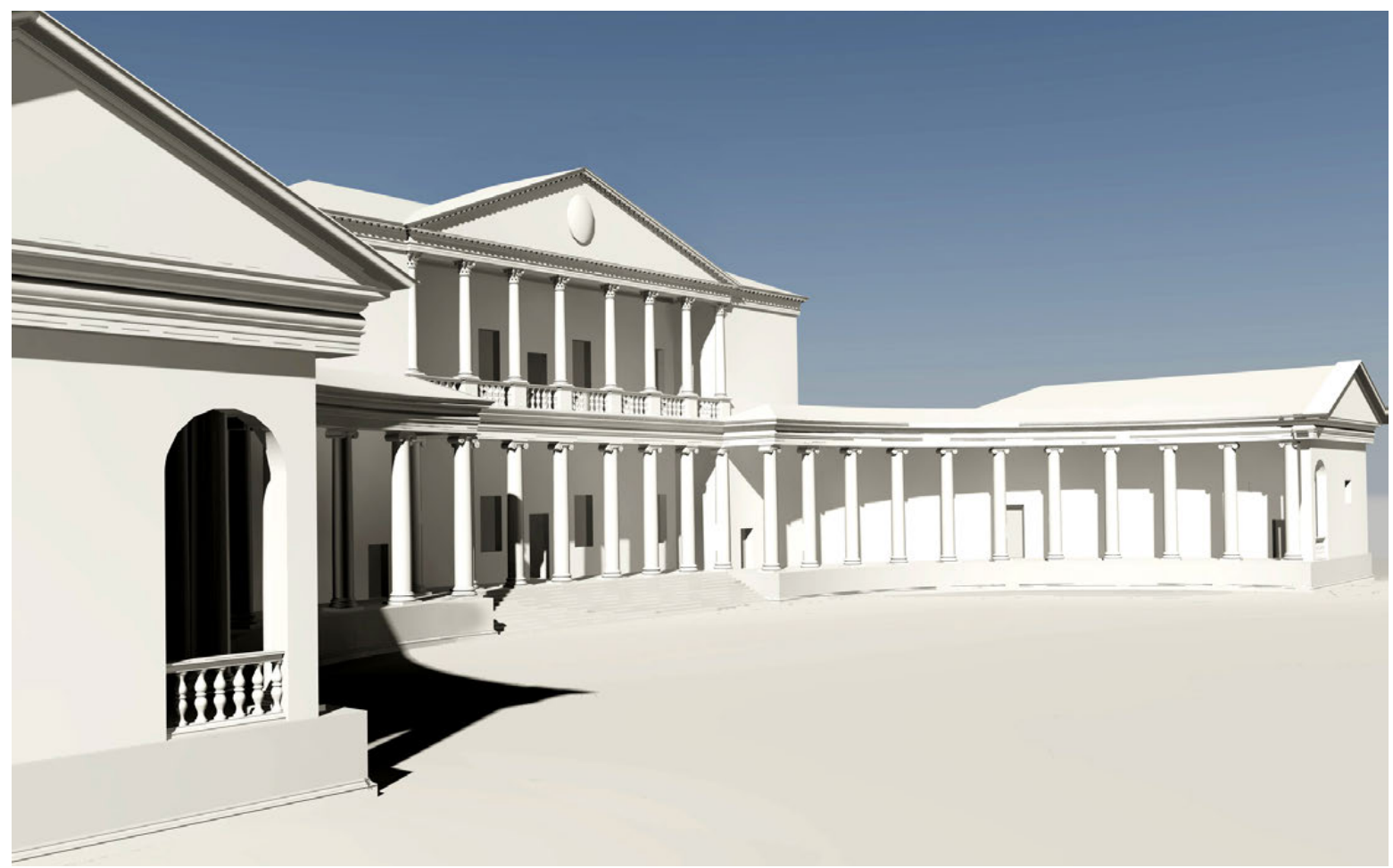

Figure 4. Virtual reconstruction: A. Palladio, Villa Mocenigo.

\subsection{D Reconstructive Hypotheses after Palladian Drawings}

For the reconstruction of 3D digital models of Palladian buildings, we used as documentary sources original drawings by Andrea Palladio for designs of villas (Fig. 4), palaces and other buildings. These drawings are preserved in various archives [e.g., RIBA, London and the Civic Art Gallery of Palazzo Chiericati, Vicenza]. We also consulted the drawings published in the second book of I quattro libri, accompanying the representations of many houses ordered from him [Palladio, 1570]. 
The original drawings are usually a plan and an elevation representing designs of unrealized villas or variants (as ideal designs) of those built by Palladio during his career. They are drawings elaborated with the aim of presenting a design, tracings juxtaposing plan and elevation, following a form of architectural representation perhaps first adopted by Antonio da Sangallo. In the drawings elaborated for a client, the measurements are depicted with care in order to not disturb the graphic quality of the drawing, reporting, in some cases, a scale bar in terms of the foot of Vicenza, or indicating, in others, the size of the rooms, widths of colonnades or porticos, or intercolumniations. The drawings depict some architectural detail: the shapes of the rooms' ceilings (rib, cloister, lunetted vaults); watercolor highlights the thickness of the walls, and the chiaroscuro effect of the openings in the façade. In some cases, these are just sketches attributable to planimetric study for projects of villas, some of which becamebuildings, others remained unbuilt.

\subsection{The projects of C. N. Ledoux for the Ideal City of Chaux}

3D models of reconstructions of Ledoux's projects were produced after drawings published in the volumes of L'Architecture [Ledoux, 1804; Ledoux, 1847; Gallet, 1991], first published in 1804, consisting of a long explanatory text illustrated by hundreds of engravings. These are detailed engravings that collect plans, sections and elevations, whose task is to describe and document the formal, geometric, distribution and architectural characteristics of different kinds of buildings (Fig. 5). In some cases they are illustrated by perspective views (Fig. 6) that render projects within a typical countrylandscape context, characterized by trails, paths, tree lines or masses of trees, mountains, rivers; some include human figures and animals. All the plates reproducing technical drawings are accompanied by a graphic bar scale in Toises du Chatelet.
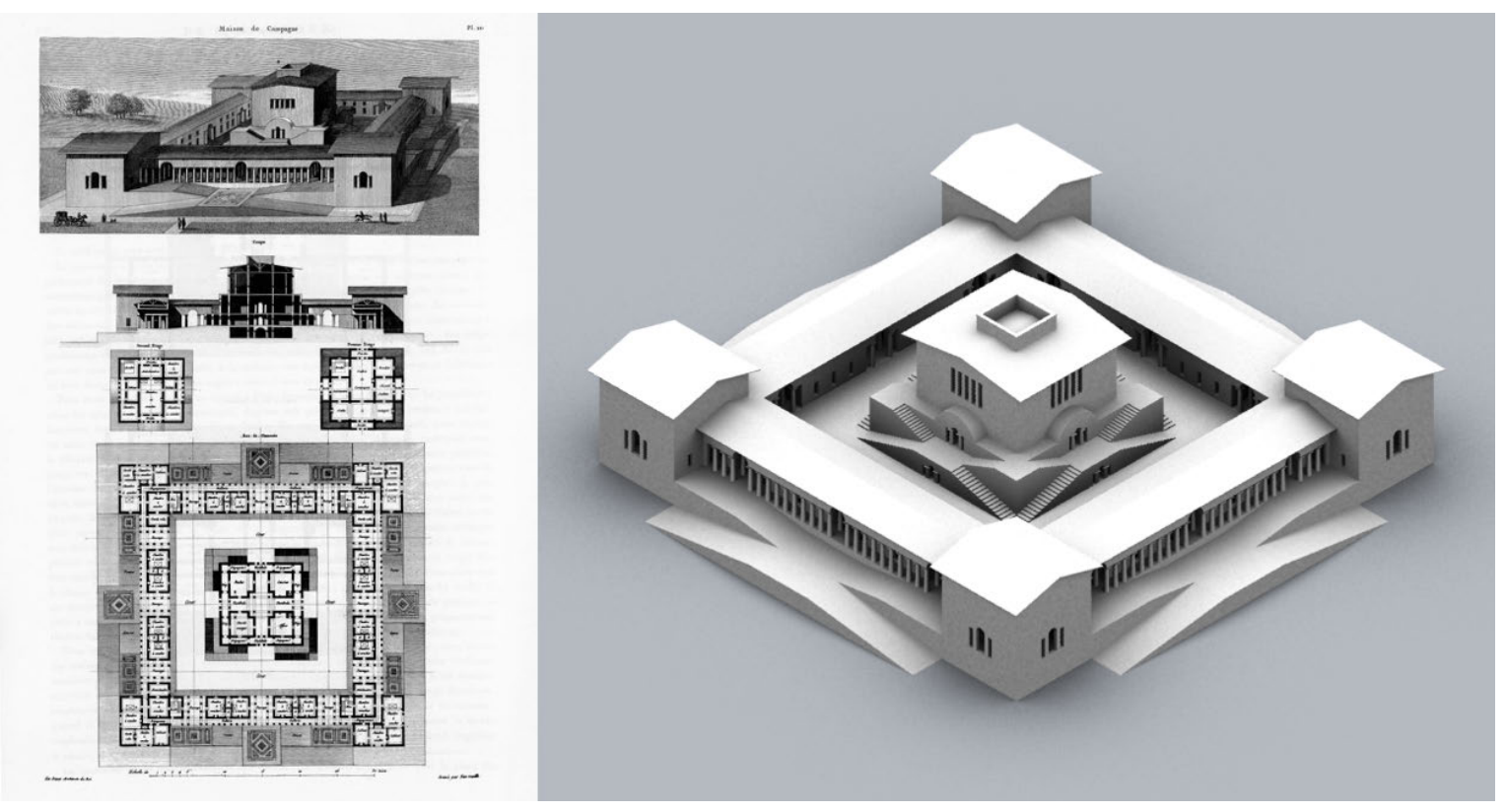

Figure 5. Virtual reconstruction: C. N. Ledoux, Maison de campagne, Planche 21. 


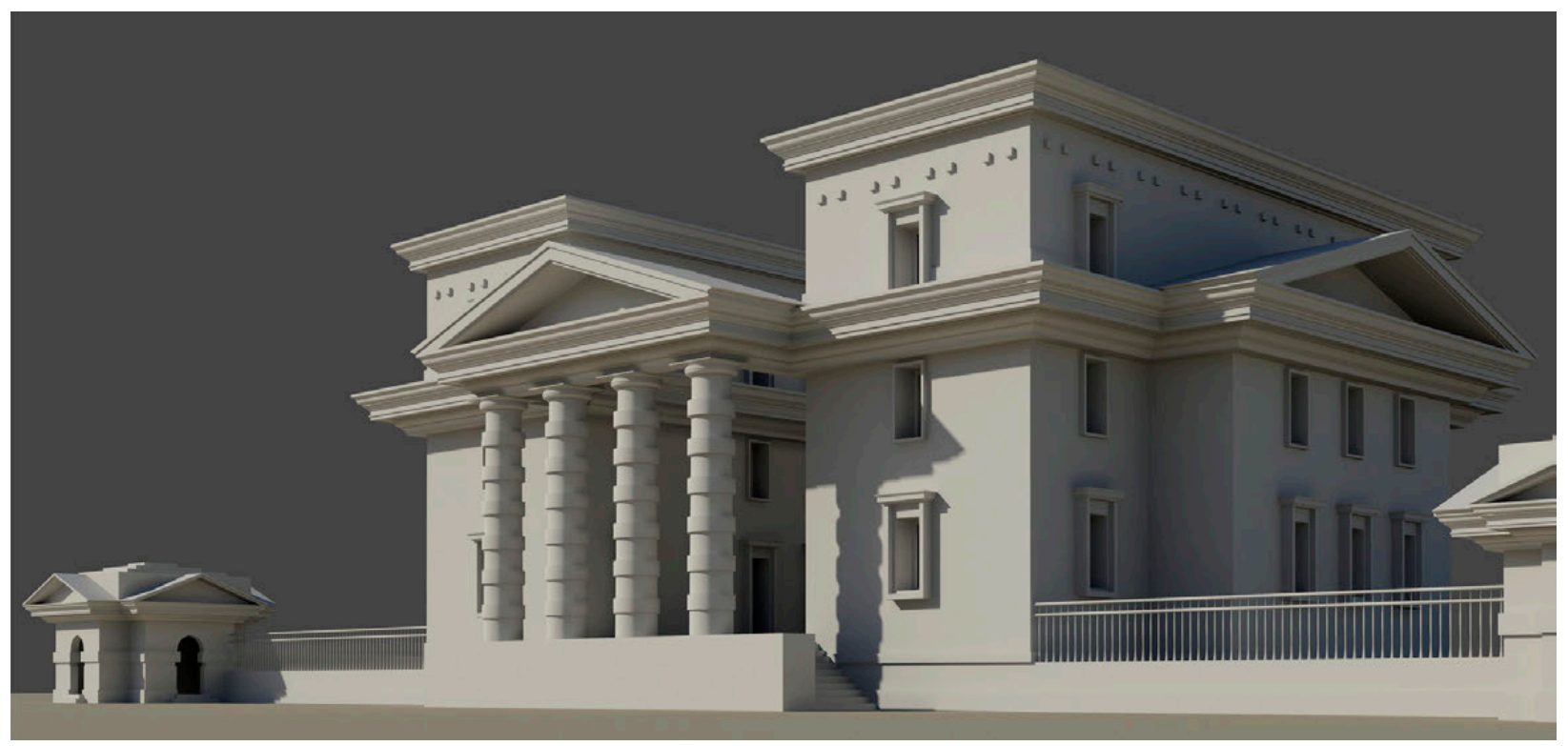

Figure 6. Virtual reconstruction: C. N. Ledoux, Chemin de Saint Denis.

\subsection{The Digital Reconstruction of Unbuilt Architecture Designed by Giovanni Antonio Antolini}

Giovanni Antonio Antolini (1753-1841) was an Italian architect, urbanist, engineer, writer, and professor at the University of Bologna and at Milan's Brera Academy. From 1797 to 1813, he worked on many important Neoclassical designs for buildings that were never constructed, probably because of the high costs arising from their visionary nature and urban scale [Antolini, 1806; Antolini, 1797]. His drawing abilities were considerable. It is not unusual to encounter inconsistencies in the hand drawn plans of many contemporary architects, especially between sections and plants, stairs and facades, but in Antolini's drawings this happens very infrequently. Furthermore, the classical orders were often detailed on documents presented with the project boards or in separate writings [Antolini, 1785; Antolini, 1803]. This means that during the digital reconstruction there is no need for many subjective interpretations and personal conjectures, or to consult other architects as references, because there are few incoherencies and omissions in Antolini's designs.

\subsection{Digital Reproduction of Original Drawings}

Alongside the considerations concerning the accuracy of the information inferred from drawings, we can consider other assessments regarding the digital reproduction of documents or original drawings. These aspects relate in particular to the accuracy of the reproduction of graphic signs and color fidelity, where, in addition to the geometric information in the drawings, we can include information regarding the treatments of the architectural surface (Fig. 7). 


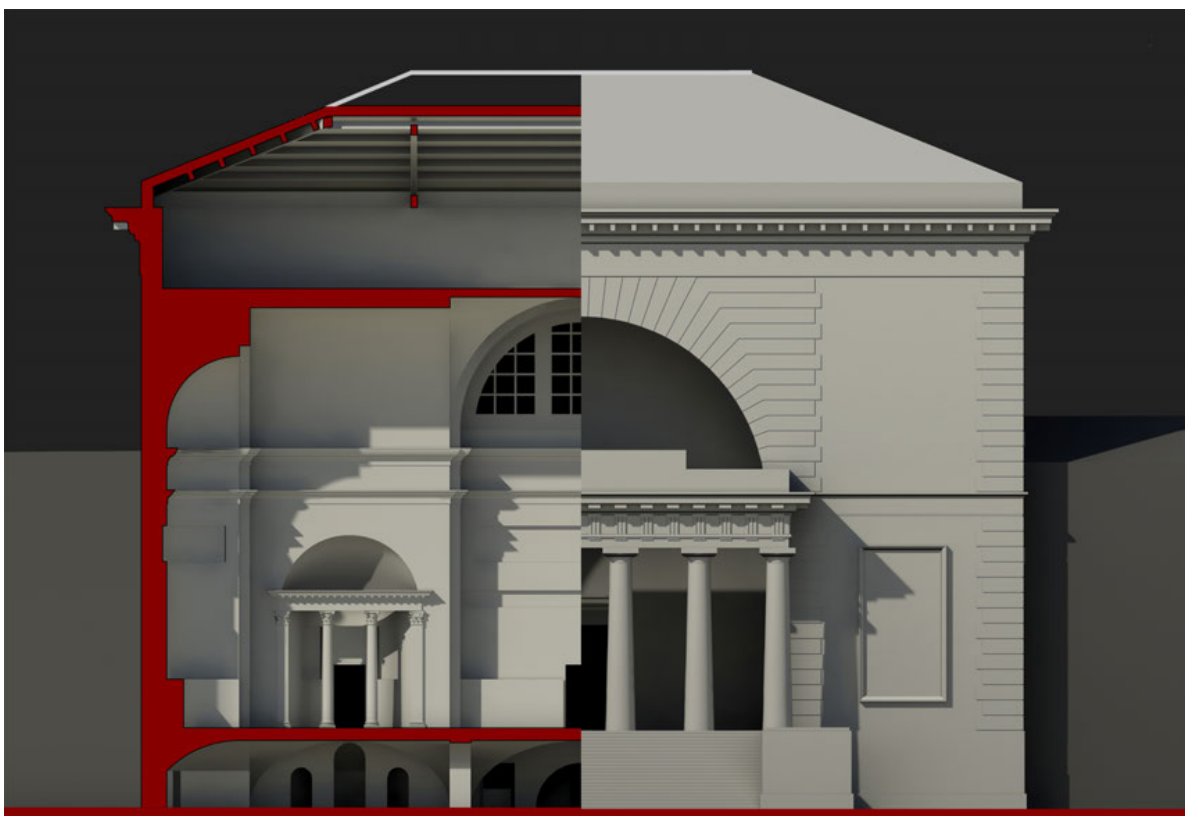

Figure 7. Virtual reconstruction: G. A. Antolini, Foro Bonaparte, Entrance of the Thermae.

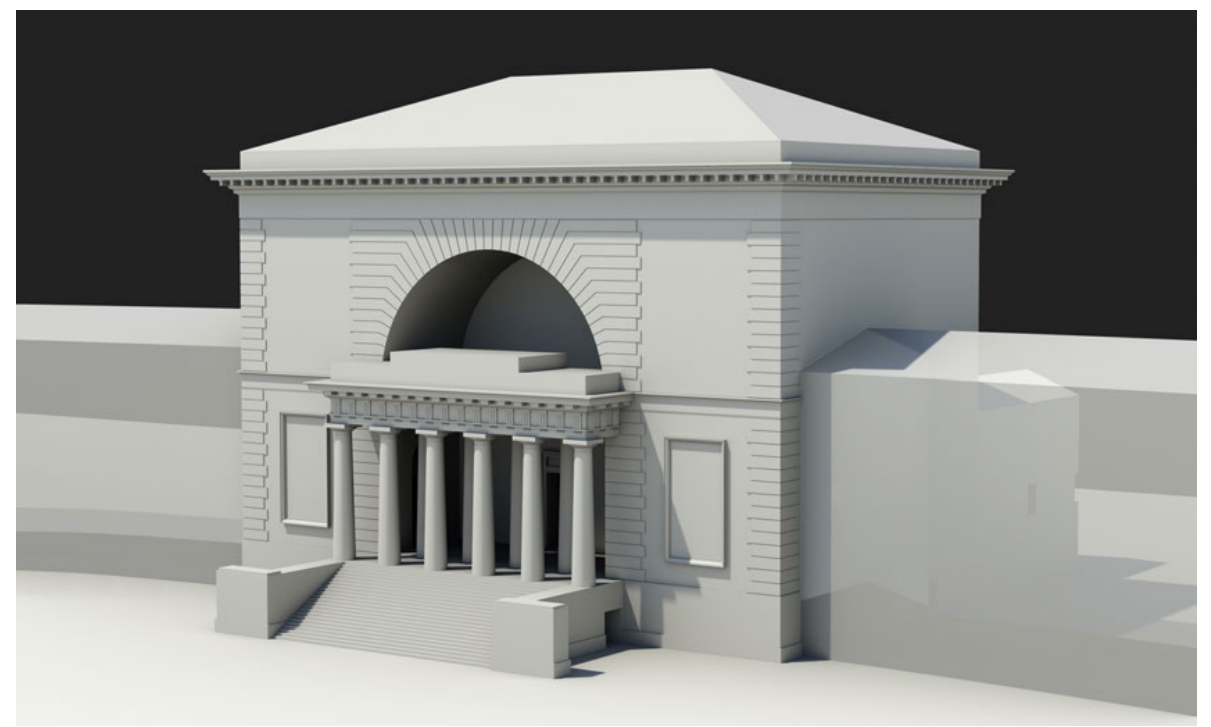

Figure 8. Virtual reconstruction: G. A. Antolini, Foro Bonaparte, Entrance of the Thermae.

Without going further into these topics related to the digital reproduction of drawings [Beltramini and Gaiani, 2003; Corsi et al., 2011], which is beyond the scope of this article, we used high-resolution scans as a digital basis for the 3D reconstructive modeling. These were obtained from original drawings or from facsimiles in books. In addition to considering the strain on the paper that was used for the scans, which was offset in most cases due to the presence of a graphic scale, the inherent precision of the drawings was estimated on the basis of the graphic sign of less thickness, according 
to the graphic representation of scale and the factor of approximation introduced by digital reproductions that were scanned. By way of example, we can affirm that the 3D digital models obtained from original drawings at a scale of 1: 100 have an accuracy of $\pm 3.5 \mathrm{~cm}$ whereas those obtained from drawings at the scale of 1:50 have an accuracy of $\pm 1.75 \mathrm{~cm}$ (Fig. 8).

\subsection{Methodological Approach to 3D Virtual Reconstruction Based on Drawing}

The hypothetical reconstruction begins with the creation of a three-dimensional model of the edifice as is inferred by the plan and elevation depicted therein. This type of reconstruction requires an analytic method of construction based on a semantic system, as not all the information necessary for completion of the model is obtainable only and univocally from the drawing itself.

As a preliminary step, we identified some design references belonging to the author's methodological sphere more or less contemporary to the case study, and to the drawing used as a source, owing to the stylistic similarities that these can present; thus they can be used as a means of verification of formal and architectural features. To solve several basic design issues, we conversely used books or treatises on architecture as references. These included the first part of Palladio's I quattro libri, as well as the handbook published by Antolini, in which the architect presents his formulas for orders, for measurements of the rooms, the design of the stairs, and for the design of architectural details (columns, pilasters, moldings, architraves, sizing of doors and windows, etc.). These are the references for the entire design system. We could not model other elements based on the information obtainable from the drawing. This required more perceptive interpretations obtained by referring to other treatises, i.e., Serlio's I Sette libri, and by focusing primarily on the building systems used at that time in order to formulate reconstruction theories that were plausible from a technical, structural and design point of view.

\subsection{The Case Study of Villa Mocenigo Based on Drawings edited by Andrea Palladio}

The case study of Villa Mocenigo by Andrea Palladio can illustrate, in an emblematic way, the theoretical considerations discussed above (Fig. 9). The reference information is provided by one Palladio's sketched plan of a villa at Dolo for Leonardo Mocenigo, stored at RIBA. The events that mark projects for the Villa Mocenigo are very well articulated. Palladio was most likely commissioned for the villa project in 1554, when it is known that Leonardo Mocenigo purchased stone for the construction in the "brolo" that he inherited from Alvise Mocenigo the Elder. This was placed in a southern lane of Naviglio Brenta, between Dolo and Paluello. The work continued with some interruptions, partly resulting from the owner's commitments abroad as ambassador to Emperor Ferdinand at least until 1564. Unfortunately in 1581, his son, Alvise the Younger, entrusted to Cesare Franco the renovation of the villa. Further work was done to make the Palladian building unrecognizable, and it was demolished at the beginning of the nineteenth century.

The villa had a traditional layout with a hallway and a pronaos with four composite columns. It is much different, however, from the plan published in the table of Palladio's treatise (f. 66), showing a building developed around a peristyle with four colonnade fronts, of which the two largest were 
framed by rustic curvilinear features. The RIBA designs propose variants on the same theme. The drawing, numbered XVI/1r in the Burlington-Devonshire Collection, represents a building reminiscent of Giuliano da Maiano's villa of Poggio Reale near Naples of 1487-88. The drawing numbered XVI/2 represents a design based on the plan of Falconetto's Villa Vescovile, and the drawing numbered $\mathrm{X} / \mathrm{lv}$ is a sketch design for the plan of a villa, similar to the project published in $I$ quattro libri. There is a central peristyle around which the villa's rooms are laid out, but with only one court, the lower one, framed by "barchesse," while the upper court is simply designed as an Italian garden. The reconstructive hypothesis shown in Fig. 9 refers, however, to the sketch numbered X/2r, which-albeit the least defined among all the ones related to the villa's design-has some characteristics that lie as an intermediate solution between the drawings cited above (XVI/1r, XVI/2, $\mathrm{X} / \mathrm{lv}$ ) and the proposal of I quattro libri.

1

Andrea Palladio, RIBA28362

$\mathrm{X} / 1 \mathrm{v}$ in the Burlington-Devonshire Collection
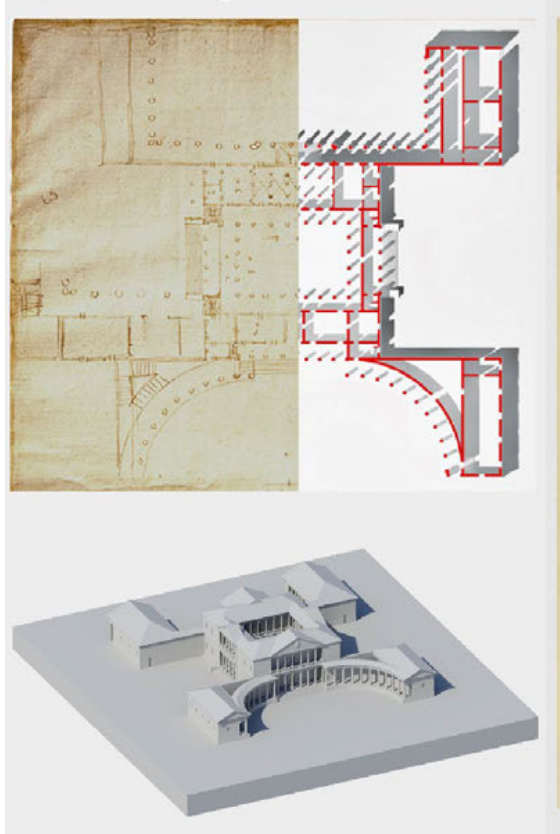

\section{Level Of Accuracy}

2

Andrea Palladio, I Quattro libri dell'architettura,

Venezia, 1570, libro II, p. [66].

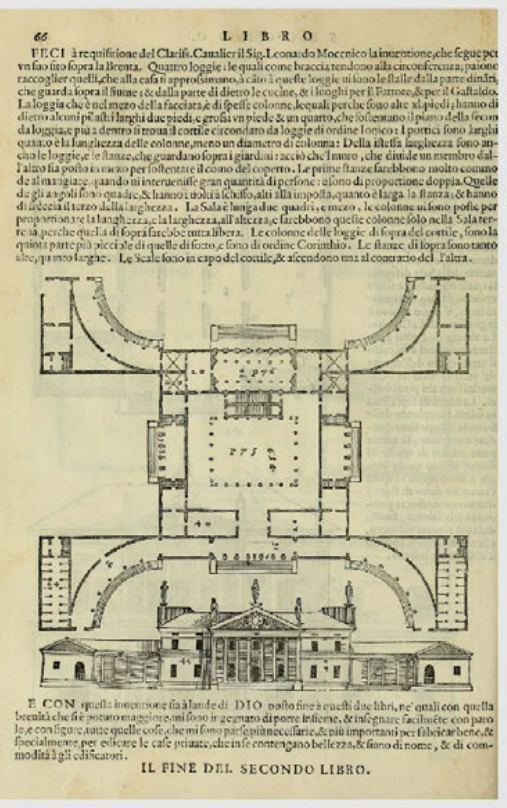

Level Of Uncertainty

3
3

Andrea Palladio, I Quattro libri dell'architettura, Venezia, 1570, libro I

Ordine Ionico, p. [29].

Ordine Cirinzio p. [38]

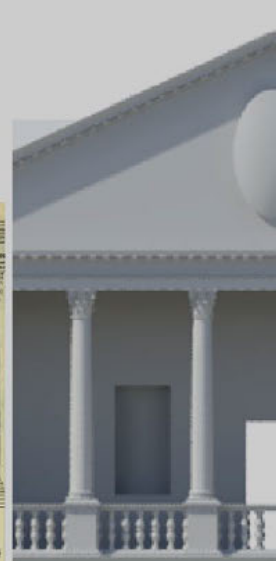

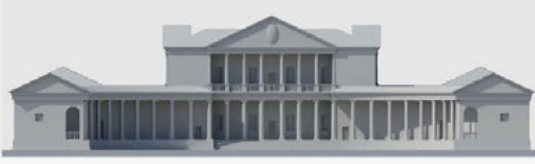

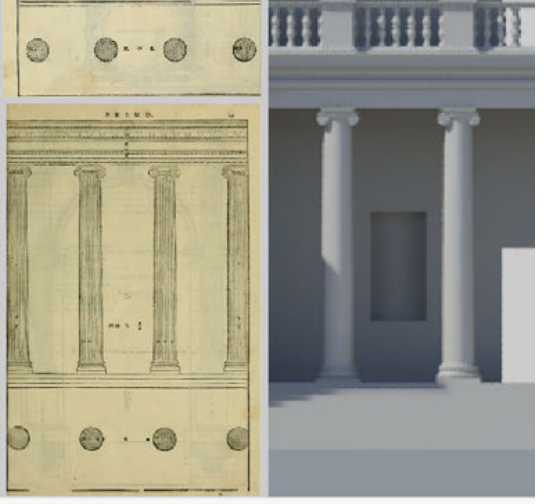

4

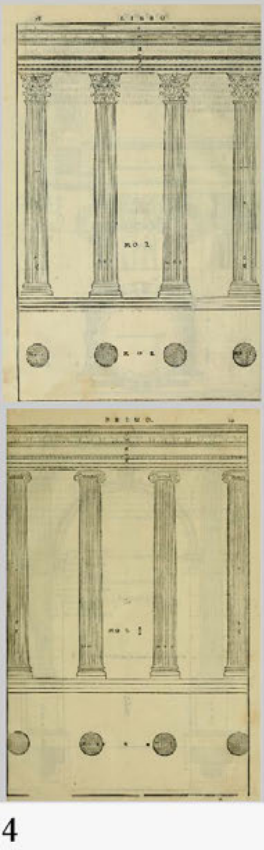

Figure 9. Virtual reconstruction: the Case Study of Villa Mocenigo designed by Andrea Palladio. 
The colonnade peristyle has a rectangular shape of 70 x 50 Vicentine feet; the lower court is framed by curvilinear "barchesse"; the upper court opens from a C-shaped colonnade with two "barchesse" on the short sides.

The sketch presents only the plan of the ground floor of the building, giving an indication of the layout of the main rooms, the positioning of the stairs, the layout of the colonnades and some measurements of the rooms. It therefore allows us to formulate a reconstructive hypothesis of the planimetric layout of the villa, with a high degree of uncertainty (Grade 2) and an intrinsic accuracy defined by the unit of measure used by Palladio, the Vicenza foot (equal to $35.6 \mathrm{~cm}$ ). The thicknesses of the walls were defined on the basis of the constructive features indicated by Palladio himself in his treatise (Grade 4) and detailed by Larry Sass [Sass, 2007] (Grade 4). As regards the elevation, as well as the information relating to the parts not defined in the RIBA X/2r sketch, the reference was the text and drawing relating to the villa Mocenigo published by Palladio in Table 66 of Book II of his treatise.

These constitute documentary sources of uncertainty of Grade 3, as they represent "data related to stylistic/contemporary similarities" in the specific data related to a different solution for the same design, made by the same architect, and with a grade of accuracy defined by the unit used by Palladio also in the treatise, which is always the Vicenza foot. Concerning the architectural details, orders, moldings and frames as a reference, the indications given in Palladio's treatise have been adopted. There we find the characteristics of the Ionic and Corinthian architectural orders, the moldings of the door, and the window frames. Such data sources reflect references of uncertainty of Grade 4, because they represent "reference to treatises written by the same architect." The highest degree of accuracy, such as the dimensions of stylistic elements (capitals, friezes, balustrades, decorations), are obtained from the diameter of the column adopted for the building (whose measurement for Villa Mocenigo is indicated in Table 66). This is assumed as a reference measurement unit (or module) in order to understand the proportions of all the other constructive and stylistic elements of the construction.

\section{CONCLUSION AND FUTURE WORK}

Even if the digital reconstruction based on architectural drawings or sketches represents only a small part of the wide range of types of reconstructive paths, the process itself is particularly significant, inasmuch as-beyond the definition of formal and geometric characteristics of an artifact-it adds to the issues related to the certainty of the data used as a source and also to the question related to the accuracy of granularity of the data itself, only partially considered in this paper.

However, we still must explore all the issues related to the formulation of the hypothetical 3D reconstruction of the material characteristics of the building that was just designed and never built. Although there does exist information related to the definition of the characteristics of the surfaces of a building (walls, floors, cornices, columns, etc.), the acquisition and the interpretation of those data always pose additional issues related to the reliability of the data itself, to its interpretation and to the certainty of the solution adopted. These are the problems related to the acquisition and interpretation of the data found in the drawings, owing to the aging that the medium (paper or other 
material) underwent-like any archaeological find-and that leads to inevitable chromatic alteration, to changes and deformations of the surface, and to losses or damage.

\section{REFERENCES}

Leon Battista Alberti. 1485. De re aedificatoria, Firenze.

Giovanni A. Antolini. 1785. L'Ordine dorico, ossia il Tempio d'Ercole nella città di Cori, Roma: Stamperia Pagliarini.

Giovanni A. Antolini. 1797. Progetto per il nuovo Borgo fuori Porta Imolese a Faenza, Coll. Archivio di Stato di Faenza.

Giovanni A. Antolini. 1802. Piano Economico-Politico del Foro-Bonaparte, Presentato coi Disegni al Comitato di Governo della Repubblica Cisalpina il dì 25 Frimale anno IX. Repubblicano. Brumale anno X Repubblicano. Milano: Agnelli.

Giovanni A. Antolini. 1803. Il tempio di Minerva in Assisi confrontato colle tavole di Palladio, Milano: Destefanis.

Giovanni A. Antolini. 1806. Descrizione del Foro Bonaparte, Parma: Bodoni.

Fabrizio I. Apollonio, Marco Gaiani, and Zheng Sun, 2013. 3D modeling and data enrichment in digital reconstruction of Architectural Heritage. ISPRS. International Archives of the Photogrammetry, Remote Sensing and Spatial Information Sciences, XL-5-W2, 43-48.

Fabrizio I. Apollonio, 2016. Classification schemes for visualization of uncertainty in digital hypothetical reconstruction. In: Sander Münster, Mieke Pfarr-Harfst, Piotr Kuroczyński, Marinos Ioannides (Eds.) 3D Research Challenges in Cultural Heritage II: How to Manage Data and Knowledge Related to Interpretative Digital 3D Reconstructions of Cultural Heritage, Cham: Springer International Publishing. 173-197.

Bakker, Geeske, Frans Meulenberg, and Jan De Rode. 2003. Truth and credibility as a double ambition: Reconstruction of the built past, experiences and dilemmas. Journal of Visualization and Computer Animation, 14, no. 3: 159-167.

Guido Beltramini, and Marco Gaiani (Eds.). 2003. Una metodologia per l'acquisizione e la restituzione dei giacimenti documentali dell'architettura. I materiali per lo studio di Andrea Palladio. Milano: POLI.design.

Edward W. Bodnar, and Clive Foss (Eds.). 2003. Cyriac of Ancona: Later travels, Cambridge, MA: Harvard University Press.

Edward W. Bodnar. 1960. Cyriacus of Ancona and Athens, Berchem: Bruxelles.

Stefano Borghini, and Raffaele Carlani. La restituzione virtuale dell'architettura antica come strumento di ricerca e comunicazione dei beni culturali: ricerca estetica e gestione delle fonti. Disegnarecon, 4(8). 71-79.

Georges Pierre Bonneau, Hans Christian Hege, Chris R. Johnson, Manuel M. Oliveira, Kristin Potter, Penny Rheingans, and Thomas Schultz. 2014. Overview and state-of-the-art of uncertainty visualization. Mathematics and Visualization 37: 3-27.

Nadia Boukhelifa, and David John Duke. 2009. Uncertainty visualization: why might it fail? In CHI Extended Abstracts'09. 4051-4056.

Ken Brodlie, Rodolfo Allendes Osorio, and Adriano Lopes. 2012. A Review of Uncertainty in Data Visualization. In John Dill, Rae Earnshaw, David Kasik, John Vince and Pak Chung Wong (Eds.), 
Expanding the Frontiers of Visual Analytics and Visualization, Springer Verlag London. 81-109 Cristiana Corsi, Marzia Faietti, Marco Gaiani, Ilaria Rossi, and Massimo Zancolich. 2011. Towards a unified and fast workflow for fine art drawing collection acquisition. In Vito Cappellini, and James Hemsley (eds). EVA 2011 Florence proceedings. Bologna: Pitagora Editrice. 76-81.

Emanuel Demetrescu. 2015. Archaeological Stratigraphy as a formal language for virtual reconstruction. Theory and practice. Journal of Archaeological Science, Vol. 57. 42-55.

Laura D. Edwards, and Elisabeth S. Nelson. 2001. Visualizing Data Certainty; a case study using Graduated Circle Maps. Cartographic perspectives, 38. 19-36.

Michel Gallet, 1991. Architecture de Ledoux. Inédits pour un tome III, Paris.

Ropertos Georgiou, and Sorin Hermon. 2011. A London Charter's visualization: The ancient hellenistic-roman theatre in Paphos. In Proceedings of International Symposium on Virtual Reality, Archaeology and Intelligent Cultural Heritage-Short and Project Papers, VAST'11. 53-56.

Karen M. Kensek. 2007. Survey of Methods for Showing Missing Data, Multiple Alternatives, and Uncertainty in Reconstructions. In CSA Newsletter, Vol. XIX, No. 3, Winter (2007).

Claude-Nicholas Ledoux. 1804. L'architecture considérée sous le rapport de l'art, des mœurs et de la législation, tome I, Paris.

Claude-Nicholas Ledoux. 1847. Architecture de C.N. Ledoux. Premier volume contenant des plans, élévations, coupes,..., edited by Daniel Ramée, 2 voll., Paris.

Patricia Lulof, Loes Opgenhaffen, and Maarten H. Sepers. 2013. The art of reconstruction documenting the process of 3D modeling: some preliminary results. In Proceedings of International Conference on Digital Heritage. 333-336

Maic Masuch, and Thomas Strothotte. 1998. Visualising ancient architecture using animated line drawings. In Proceedings of the IEEE Conference on Information Visualization. 261-266.

Charles Mitchell. 1974. Ciriaco d'Ancona: Fifteen-century Drawings and Description of the Parthenon. In V. Bruno (Ed.). The Parthenon, New York. pp. 111-123.

Sander Münster, Wolfgang Hegel, and Cindy Kröber. 2016. A Model Classification for Digital 3D Reconstruction in the Context of Humanities Research. In: Sander Münster, Mieke Pfarr-Harfst, Piotr Kuroczyński, Marinos Ioannides (Eds.) 3D Research Challenges in Cultural Heritage II: How to Manage Data and Knowledge Related to Interpretative Digital 3D Reconstructions of Cultural Heritage, Cham: Springer International Publishing. 3-31.

Valentino Nizzo. 2010. Prima della Scuola di Atene: alle origini dell'"archeologia" italiana in Grecia. In Forma urbis. Supplemento al n. 4, aprile 2010.

Mathias Otto, Tobias Germer, Hans Christian Hege, and Holger Theisel. 2010. Uncertain 2D Vector Field Topology. Computer Graphics Forum, 29, no. 2: 347-356.

Andrea Palladio. 1570. I Quattro Libri dell'Architettura, Venezia.

Alex T. Pang, Craig M. Wittenbrink, and Suresh K. Lodha. 1997. Approaches to uncertainty visualization. The Visual Computer, 13(8). 370-390.

Alex T. Pang, and J. Furman. 1994. Data quality issues in visualization. In Proceedings of SPIE. Vol. 2278, Visual Data Exploration and Analysis. 12-23.

Mieke Pfarr-Harfst. 2016. Typical Workflows, Documentation Approaches and Principles of 3D Digital Reconstruction of Cultural Heritage. In: Sander Münster, Mieke Pfarr-Harfst, Piotr Kuroczyński, Marinos Ioannides (Eds.) 3D Research Challenges in Cultural Heritage II: How to Manage Data and Knowledge Related to Interpretative Digital 3D Reconstructions of Cultural 
Heritage, Cham: Springer International Publishing. 32-46.

Marta Perlinska. 2014. Palette of possibilities. PhD Thesis. Lund University, Department of Archaeology and Ancient History.

Larry Sass, 2007. A Palladian construction grammar - design reasoning with shape grammars and rapid prototyping. Environment and Planning B: Planning and Design, 34, 87-106.

Sebastiano Serlio. 1584. Tutte l'opere d'architettura di Sebastiano Serlio Bolognese, Venezia.

Thomas Strothotte, Maic Masuch, and T. Isenberg. 1999. Visualizing Knowledge about Virtual Reconstructions of Ancient Architecture. In Proceedings of Computer Graphics International. 36-43.

Judi Thomson, Elizabeth Hetzler, Alan Maceachren, and Mark Gahegan. 2005. A typology for visualizing uncertainty. In Proceedings of SPIE. Vol. 5669. 146-157.

Maria D. Vico Lopez. 2012. La "Restauración Virtual" según la interpretación arquitectonico constructiva: metodologia y aplicación al caso de la Villa de Livia. PhD thesis. Universitat Politecnica de Catalunya.

Marco Vitruvio Pollione. 1556. I Dieci Libri dell'Architettura. Commentati da Monsignor Barbaro eletto Patriarca di Aquileggia, Venezia: Marcolini.

Torre Zuk, Sheelagh Carpendale, and W. D. Glanzman. 2005. Visualizing temporal uncertainty in 3D virtual reconstructions. In Proceedings of the 6th International Conference on Virtual Reality, Archaeology and Intelligent Cultural Heritage, VAST'05. 99-106.

Received March 2017; revised July 2017; accepted August 2017. 